\title{
Pals, Problems, and Personality: The Moderating Role of Personality in the Longitudinal Association Between Adolescents' and Best Friends' Delinquency
}

\author{
Rongqin Yu,' Susan Branje,' Loes Keijsers,' \\ Hans M. Koot, ${ }^{2}$ and Wim Meeus ${ }^{1,3}$ \\ 'Utrecht University, The Netherlands \\ ${ }^{2} \mathrm{VU}$ University Amsterdam, The Netherlands \\ ${ }^{3}$ Tilburg University, The Netherlands
}

\begin{abstract}
We examined the potential moderating role of Block's personality types (i.e., overcontrollers, undercontrollers, and resilients) on the longitudinal associations between adolescents' and their best friends' delinquency. Across three annual waves, 497 Dutch adolescents ( 283 boys, $M_{\mathrm{Age}}=\mathrm{I} 3$ years at Wave I) and their best friends reported on their delinquent behaviors. Adolescents' three personality types were obtained by latent class growth analysis on their annual reports on Big Five personality. A three-group cross-lagged panel analysis was performed on three waves of data. Delinquency of overcontrollers was predicted by their best friends' delinquency, whereas delinquency of undercontrollers and resilients was not. Delinquency of undercontrollers and resilients predicted their best friends' delinquency, but overcontrollers' delinquency did not. These findings suggest that personality may play an important role in adolescents' susceptibility to the influence of friends' delinquency, as well as in youths' ability to influence friends through their own delinquency.
\end{abstract}

Adolescents' delinquency is strongly associated with the delinquency of their friends (Haynie \& Osgood, 2005; Sutherland, 1947). This similarity in delinquent behaviors may be caused not only by the selection of similar friends or by the deselection of dissimilar ones, but also by a process in which friends influence each other to engage in similar behaviors (Burk, Steglich, \& Snijders, 2007). Through influence processes, friends may become increasingly similar in their delinquent behaviors over time. However, not all adolescents may be equally affected by, or affect, their peers. Some adolescents might be more vulnerable to their peers' delinquency, and some might have a stronger influence on their peers' delinquency. Although research on moderators of peer influence has been a rapidly growing area in the past decade (Cohen \& Prinstein, 2006), the study of personality characteristics as potential moderators remains relatively rare. The aim of the present study, therefore, is to examine how adolescents' personality types moderate the ways in which adolescents and their best friends influence each others' delinquency.

Empirical studies suggest that individual characteristics may moderate the extent to which adolescents are influenced by or exert influence on others' behavior (Brechwald \& Prinstein, 2011). For instance, the association between adoles- cents' deviant peer affiliation and their later antisocial behavior was weaker for adolescents with higher self-regulation ability than for those with lower self-regulation ability (Gardner, Dishion, \& Connell, 2008). In addition, adolescent boys with different levels of disruptiveness were differently affected by their deviant best friends. The delinquency of moderately disruptive boys but not the delinquency of highly disruptive or conforming boys was predicted by their best friends' deviant behaviors over time (Vitaro, Tremblay, Kerr, Pagani, \& Bukowski, 1997). Further, psychopathological symptoms, such as anxiety and depression, moderated the link between adolescents' and their friends' behaviors. In particular, high depressive or social anxiety symptoms magnified the association between adolescents' and their peers' aggressive and violent behaviors (Cohen \& Prinstein, 2006; Prinstein, Boergers, \& Spirito, 2001). Moreover, adolescents' peer status plays a role in their ability to exert influence on the behaviors of their peers. Adolescents displayed greater conformity to

\footnotetext{
Correspondence concerning this article should be addressed to Rongqin Yu, Research Centre Adolescent Development, Utrecht University, P.O. Box 80.140, 3508 TC Utrecht, The Netherlands. Email: r.yu@uu.nl.
} 
aggressive or health risk behaviors of peers with higher status than to those with lower status (Cohen \& Prinstein, 2006). These findings imply that individual characteristics can play an important role in the association between adolescents' and their peers' deviant behaviors.

\section{The Role of Personality in the Link between Adolescents' and Friends' Delinquency}

Recent work starts to deal with the moderating role of personality traits in peer influences on delinquency. One study examined the moderating role of psychopathic traits on peer influence processes. The results suggested that delinquency of adolescents with higher levels of callous-unemotional and grandiose-manipulative traits was less influenced by, but more influential upon, their friends' delinquency, than the delinquency of adolescents who were lower in these psychopathic traits (Kerr, Van Zalk, \& Stattin, 2012). Another study only found an association between delinquency of adolescents and their friends among adolescents with lower levels of impulsivity, but not among adolescents displaying higher levels of impulsivity (Vitulano, Fite, \& Rathert, 2010). Thus, although research on the moderating role of personality traits is still rare, these studies demonstrate that personality could magnify or mitigate the link between delinquency of adolescents and their friends.

Previous studies examining personality characteristics as moderators in peer influence processes exclusively used a variable-centered approach, which assesses the correlational structure of the personality traits across persons within a particular population. A person-centered approach has been considered as an important and necessary complement to the variable-centered approach in studies involving personality (Meeus, Van de Schoot, Klimstra, \& Branje, 2011). This approach enables us to delineate typical configurations of personality traits within the person and thus assesses the common within-person structure of personality. Therefore, in the current study, we examined the role of personality type, or the patterning of personality traits within the individual, in the longitudinal associations between adolescents' and their best friends' delinquency.

The most commonly used person-centered approach to personality was based on personality theory of ego-control and ego-resiliency by Block and Block (1980). Ego-control refers to containing versus expressing emotional and motivational impulses, and ego-resiliency refers to the dynamic capacity of individuals to adjust their modal levels of ego-control, depending on environmental demands (Block \& Block, 1980). Studies have suggested that three personality types - resilients, undercontrollers, and overcontrollers - could be constructed as specific combinations of ego-control and ego-resilient (Asendorpf, Borkenau, Ostendorf, \& Van Aken, 2001; Hart, Hofmann, Edelstein, \& Keller, 1997; Robins, John, Caspi,
Moffitt, \& Stouthamer-Loeber, 1996). Specifically, resilients are characterized by a high level of ego-resiliency and a medium level of ego-control. Overcontrollers and undercontrollers both have a low level of ego-resiliency, but differ on ego-control. Overcontrollers have a high level of ego-control and undercontrollers have a low level of ego-control (e.g., Robins et al., 1996). These three personality types have been identified in various samples, including children, adolescents, and adults, by using various methods such as $Q$ factor analysis or cluster analysis (Asendorpf et al., 2001; Klimstra, Hale, Raaijmakers, Branje, \& Meeus, 2010; Robins et al., 1996).

\section{Differential Levels of Delinquency by Personality Types}

Individuals with different personality types are distinguishable on their levels of delinquency. In particular, undercontrollers have significantly higher levels of delinquency than overcontrollers and resilients. Between the latter two, there are generally no significant differences (Klimstra et al., 2010; Robins et al., 1996). It is not clear, however, whether adolescents with different personality types differ in susceptibility to or ability to exert peer influence on delinquency.

Among individuals with different personality types, resilients are often considered a well-adjusted group, since they can respond adaptively and flexibly toward situational demands. Overcontrollers and undercontrollers are the more maladjusted groups, exhibiting little adaptive flexibility when encountering stressful situations (Block \& Block, 1980). A recent study showed that personality types mature in the direction of resiliency, with an increasing number of resilient adolescents with age (Meeus et al., 2011). In other words, resilients are considered as psychologically more mature than overcontrollers and undercontrollers. Recent work suggests that vulnerability to peer influence might become weaker as a function of developmentally normative psychosocial maturation (Allen, Porter, \& McFarland, 2006; Brechwald \& Prinstein, 2011; Sumter, Bokhorst, Steinberg, \& Westenberg, 2009). Following this line of reasoning, it may therefore be that resilients are less affected by the delinquency of their peers than overcontrollers and undercontrollers.

Although undercontrollers may be more vulnerable to their best friends' delinquency because of their less mature personality, it is possible that undercontrollers, who have higher delinquency than overcontrollers and resilients, could become a "role model" for their best friends. Adolescents face a need to fill the gap between their biological maturation and social opportunities to be fully acknowledged as adults, and peer delinquency may be attractive to adolescents because it may be a statement of independence or a way to evidence maturation (Moffitt, 1993). It is not clear, therefore, whether undercontrollers' higher delinquency is an outcome of their higher susceptibility to their best friends' delinquent behaviors because of immaturity, or a source of influence on their best friends' delinquency during adolescence. 
In addition, some studies suggested that overcontrollers might be more likely to be influenced and less influential in friendships. In particular, compared to resilients and undercontrollers, overcontrollers are less decisive and assertive, less confident, and more anxious in social interaction, which was positively related to vulnerability to peer influence (Cohen \& Prinstein, 2006; Hart et al., 1997). Thus, they might be particularly more likely to be influenced and less influential in their friendships in delinquency development.

\section{The Present Study}

Although we could not formulate specific hypotheses based on the current literature, it seems reasonable to suspect that personality types might magnify or mitigate peer influence processes between adolescents' and their best friends' delinquency. Therefore, in the current study, we examined the moderating role of the three personality types in the extent to which adolescents influence each others' delinquency. Specifically, we tested whether individuals with different personality types differed in their susceptibility to the influence of their best friends' delinquency and their ability to exert influence on their best friends' delinquency over 3 years.

\section{METHOD}

\section{Sample}

Participants came from an ongoing longitudinal study, Research on Adolescent Development And Relationships (RADAR; Van Lier et al., 2011).

Three waves of data were used in the current study. The study consists of 497 Dutch early adolescents ( 283 boys), with a mean age of 13.0 years $(S D=0.52)$ at the first measurement (T1). Of the adolescents, $95.2 \%$ identified themselves as being Dutch, and $10.8 \%$ came from families of low socioeconomic status (SES) (i.e., both parents were unemployed or held an elementary job; Statistics-Netherlands, 1993). Of the total sample of 497 adolescents, all of them reported having a friend at T1. Among them, 50.1\% $(n=249)$ had the same best friends participating at each wave, $28.5 \%(n=141)$ changed best friends once over the three waves, and $6.2 \%(n=31)$ changed best friends every wave. Best friends did not participate in all the waves for all adolescents: $3.6 \%(n=18)$ had the same best friend participating in two of the three waves, 5.8\% $(n=29)$ had a best friend participating in one of the three waves, and $5.8 \%(n=29)$ of adolescents' best friends did not provide data on their delinquency. There was no significant difference in the level of delinquency of adolescents with best friends participating in at least one wave and adolescents whose best friends did not provide data on delinquency, $F(1,402)<1, r=.02$. In addition, $11.7 \%(n=58)$ of the adolescents did not have information on friendship stability.

The attrition was low in the current study (i.e., $4.6 \%$ dropout over the three waves). For each variable, a maximum of $17.1 \%$ of the cases was missing (the average percentage of missing values per variable was $11.8 \%$ across the three measurements). The pattern of missing values was evaluated with Little's MCAR test and found to be completely at random, $\chi^{2}(N=497,101)=91.33, p=.74$. Therefore, we applied full information maximum likelihood for our model estimations.

\section{Procedure}

The target adolescents were recruited from various Dutch elementary schools. The target adolescents were asked to invite their best friend to participate. A description of the study was sent to the target adolescents' and the best friends' home address, and parents and adolescents provided informed consent to participate. Adolescents and best friends filled out various questionnaires during the annual home visits (with one-year interval), supervised by trained research assistants. Both of them received $€ 15$ as a reward for their participation in each wave. Confidentiality was ensured before participation. The study was approved by the ethical-medical committee of University Medical Centre Utrecht.

\section{Measures}

Youths' Delinquent Behaviors. Adolescents and their best friends independently reported on their involvement in 30 delinquent behaviors in the past year, such as vandalism, shoplifting, and selling stolen goods. This scale was based on a large international comparative study on delinquency (Enzmann et al., 2010). Youths responded on a 5-point scale, ranging from 0 (never) to 4 (more than ten times). We adopted a variety measure rather than a frequency measure, as the former measure is considered more accurate in indicating the severity of an individual's delinquency than the latter measure. The reason is that minor offenses usually occur more frequently than serious offenses. Thus, in frequency scale, minor offenses get a larger weight than serious offenses (Bendixen, Endresen, \& Olweus, 2003). To calculate variety in delinquency acts, we recoded all delinquent items into $0 / 1$ variables (i.e., never vs. at least once) and summed across the 30 delinquent behaviors. Measures like this have been widely used and are considered to be reasonably reliable and valid (Junger-Tas \& Marshall, 1999). The Cronbach's alphas of the scale were acceptable, ranging from .83 to .86 across three waves.

Classification of Adolescents' Personality Types. We assessed adolescents' and their best friends' personality using a shortened Dutch version of Goldberg's Big Five questionnaire (Gerris et al., 1998). Using 30 Big Five personality markers, five personality dimensions (each dimension with six items) were assessed: Extraversion (e.g., talkative), Agreeableness (e.g., sympathetic), Conscientiousness (e.g., systematic), Neuroticism (e.g., worried, reverse-scored), and Openness to Experience (e.g., creative). Adolescents and their best friends 
responded on a 7-point Likert scale, ranging from 1 (very untrue) to 7 (very true). Prior studies have shown this instrument to have adequate reliability and validity (Branje, van Lieshout, \& Gerris, 2007). In the current study, Cronbach's alphas ranged from .72 to .88 across waves. Several studies used longitudinal data on the Big Five personality traits to constitute the developmental typology of personality types (Branje, Hale, Frijns, \& Meeus, 2010; Klimstra et al., 2010). Three developmental types of personality were consistently identified and reliably related to different kinds of problem behaviors. Namely, resilients were relatively free from problem behaviors, overcontrollers were more prone to internalizing problem behaviors, and undercontrollers were more prone to externalizing problem behaviors. We also constituted the developmental types of personality with three annual waves of Big Five data.

To examine the developmental typology of the target adolescents' personality, we used Mplus 6 (Muthén \& Muthén, 2010) to perform a multivariate latent class growth analysis (LCGA; Nagin, 2005) with adolescents' Big Five personality scores across three waves. LCGA is designed to find the smallest number of classes capturing the most variance among individuals in initial levels (i.e., intercept) and change rate (i.e., slope) of the variables under observation. We used multiple criteria to determine the model with the optimal number of latent classes (i.e., developmental personality types). First, we used the sample s ize adjusted Bayesian information criterion (SSA-BIC; Schwarz, 1978) and the Lo-Mendell-Rubin likelihood ratio test (LMR-LRT; Lo, Mendell, \& Rubin, 2001). The optimal model has the lowest SSA-BIC, and a significant LMRLRT indicates that a model with $k$ classes is better than a model with $k-1$ classes. Second, we considered the theoretical meaningfulness of the classes. That is, if an additional class was only a slight variation of a previously extracted class, the most parsimonious solution was chosen (Muthén \& Muthén, 2000).
In addition, we checked whether the model had adequate entropy, which indicates classification accuracy. It ranges from .00 to 1.00 , with higher figures indicating a more accurate classification (Hix-Small, Duncan, Duncan, \& Okut, 2004).

A three-class solution was the best fit to our data. In particular, the SSA-BICs for the models with 1-4 classes were 20066.94, 19266.58, 18708.32, and 18476.79, respectively. Although the SSA-BIC figure for the model with a 4-class solution was lower than the SSA-BIC value for the model with a three-class solution, the LMR-LRT indicated that adding a fourth class did not result in an improvement of the model $(p=.10)$. In addition, the four-class model added a class that was highly comparable to one of the three classes in the threeclass model. Moreover, the model for the three-class solution had high entropy (i.e., .82), indicating high classification accuracy. Entropies for models with 2-4 classes were .79, .82, and .82 , respectively. Hence, we chose the three-class solution as the final classification. Table 1 presents the three-class model, with the intercepts (i.e., mean level) and slopes (i.e., average change per year) of the personality characteristics for the three personality types.

Among our 497 target adolescents, resilients $(n=170)$ scored moderate to high on all Big Five personality characteristics, overcontrollers $(n=127)$ scored particularly low on Extraversion and Emotional Stability, and undercontrollers $(n=200)$ scored low on Agreeableness, Conscientiousness, and Openness. These results were comparable to previous studies (e.g., Klimstra et al., 2010). In addition, only one out of 15 slopes was significantly different from zero (i.e., undercontrollers' Emotional Stability increased across waves). This is consistent with a previous study indicating substantial stability in personality development within each personality type during adolescence (Klimstra et al., 2010).

The distribution of gender differed significantly in the three personality types, $\chi^{2}(N=497,2)=12.37, p=.00, \varphi=.16$.

Table I Intercepts and Slopes of Big Five Personality Dimensions

\begin{tabular}{|c|c|c|c|}
\hline Intercept & $M(95 \% \mathrm{Cl})$ & $M(95 \% \mathrm{Cl})$ & $M(95 \% \mathrm{Cl})$ \\
\hline Agreeableness & $5.62^{* *, b}[5.46,5.77]$ & $4.93^{* *, c}[4.74,5.13]$ & $\left.5.9\right|^{* *, a}[5.77,6.05]$ \\
\hline Conscientiousness & $4.44 * *, a[4.18,4.70]$ & $3.57^{* *, b}[3.38,3.77]$ & $4.13^{* *, a}[3.81,4.67]$ \\
\hline Emotional Stability & $3.5 \mathrm{I}^{* *, \mathrm{~b}}[3.20,3.83]$ & $4.70^{* *, a}[4.53,4.89]$ & $4.79 * *, a[4.59,4.98]$ \\
\hline Extraversion & $-.07^{\mathrm{a}}[-.21, .07]$ & $.04^{\mathrm{a}}[-.04, .12]$ & $.02^{\mathrm{a}}[-.07, . \mathrm{II}]$ \\
\hline Agreeableness & $.00^{\mathrm{a}}[-.07, .07]$ & $.0 \mathrm{I}^{\mathrm{a}}[-.06, .08]$ & $.0 \mathrm{I}^{\mathrm{a}}[-.05, .06]$ \\
\hline Conscientiousness & $-.0 \mathrm{I}^{\mathrm{a}}[-.10, .09]$ & $-.05^{\mathrm{a}}[-.12, .03]$ & $.01^{\mathrm{a}}[-.08, .10]$ \\
\hline Emotional Stability & $.05^{\mathrm{a}}[-.08, .17]$ & $.10^{*, a}[.01, .20]$ & $.04^{a}[-.05, .13]$ \\
\hline Openness & $-.0 \mathrm{I}^{\mathrm{a}}[-.08, .07]$ & $-.02^{\mathrm{a}}[-.10, .06]$ & $.04^{\mathrm{a}}[-.04, .1 \mathrm{I}]$ \\
\hline
\end{tabular}

Note. $\mathrm{Cl}=$ confidence interval. Within a row, different superscripts indicate significant differences $(p<.05)$ between resilients, undercontrollers, and overcontrollers in Extraversion, Agreeableness, Conscientiousness, Emotional Stability, and Openness. $* p<.05 . * * p<.01$. 
Boys were more likely to be classified as undercontrollers than girls $\left(41.64 \%\right.$ and $31.78 \%$, respectively; $\chi^{2}[N=497$, $1]=11.20, p=.00, \varphi=.15)$, but less likely to be classified as overcontrollers $(21.20 \%$ and $31.31 \%$, respectively; $\left.\chi^{2}[N=497,1]=6.54, p=.01, \varphi=.11\right)$. Moreover, the prevalence of personality types did not differ for adolescents with stable versus unstable best friendships, $\chi^{2}(N=439,2)=0.53$, $p=.77, \varphi=.03$, neither for adolescents with reciprocal versus nonreciprocal best friendships at $\mathrm{T} 1, \chi^{2}(N=497,2)=0.19$, $p=.91, \varphi=.02$. In addition, we constituted the personality type of best friends with the same method as for constituting personality types for the target adolescents. A chi-square test revealed that personality type of best friends was unrelated to that of the target adolescents, $\chi^{2}(N=497,6)=6.25, p=.40$, $\varphi=.11$.

Adolescent delinquency was significantly related to personality type. Undercontrollers had a significantly higher variety in delinquency than overcontrollers and resilients (i.e., $\mathrm{M}$ $[S D]=2.27$ [2.94] vs. 1.44 [2.40] and 1.29 [1.59], respectively; both $p \mathrm{~s}=.00$ ), yet delinquency of overcontrollers and resilients did not significantly differ $(p=1.00)$. Moreover, delinquency of undercontrollers' best friends was significantly higher than that of overcontrollers' best friends (i.e., $\mathrm{M}$ $[S D]=2.81[3.56]$ vs. $1.69[1.95] ; p=.00)$, whereas there were no significant differences in delinquency between overcontrollers' and resilients' best friends (i.e., $\mathrm{M}[S D]=1.69$ [1.95] vs. 2.16 [1.89]; $p=.24$ ), nor between undercontrollers' and resilients' best friends (i.e., $\mathrm{M}[S D]=2.81$ [3.56] vs. 2.16 [1.89]; $p=.39)$.

\section{Analytical Strategy}

To answer our research questions, we performed a three-group cross-lagged panel, which enabled us to test the role of personality on the reciprocal over-time effect between adolescents' and their best friends' delinquency in a longitudinal design (Kline, 2011). We used robust maximum likelihood (MLR; Satorra \& Bentler, 2001) to take the non-normal distribution of delinquency into account. Groups were based on the three personality types (i.e., overcontrollers, undercontrollers, and resilients). The model included annual measurements of adolescents' and their best friends' delinquency, stability paths of adolescents' and best friends' delinquency, the withinwave correlations between adolescents' and best friends' delinquency, the cross-lagged paths from adolescents' delinquency to best friends' delinquency one year later, and the crosslagged paths from best friends' delinquency to adolescents' delinquency one year later (see Figure 1).

To test whether the associations between adolescents' and best friends' delinquency differed between the personality types, we compared a fully constrained baseline model (M0), in which all longitudinal parameters were constrained to be time invariant (see Results section), with models (M1-M7) in which we unconstrained sets of parameters across different personality types. In Model M1, the stability paths of adoles-

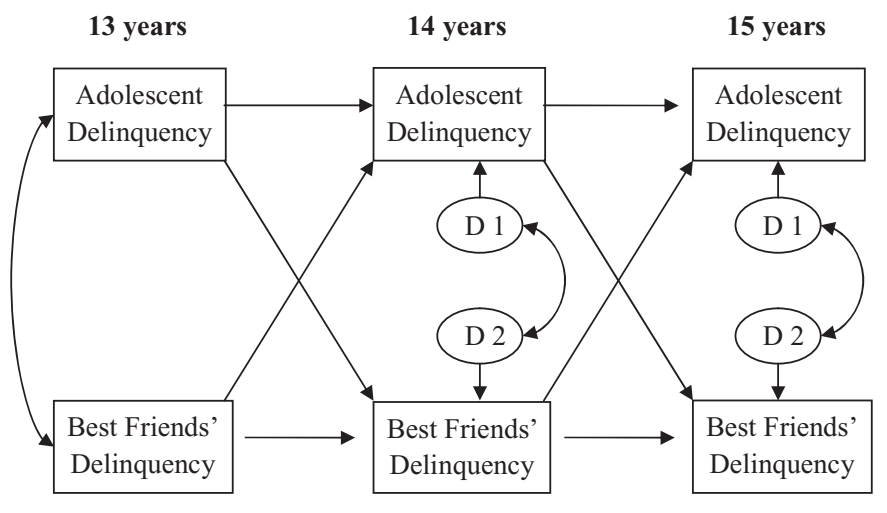

Figure I Cross-lagged model on moderating effect of personality types between adolescents' and best friends' delinquency. $\mathrm{D}=$ disturbance.

cents' delinquency were unconstrained across personality types, and in Model M2, the stability paths of best friends' delinquency were unconstrained. In Models M3 and M4, respectively, T1 within-wave associations and T2/T3 withinwave associations between adolescents' delinquency and best friends' delinquency were freely estimated across personality types. In Model M5, cross-lagged paths from adolescents' delinquency to best friends' delinquency were unconstrained, and in Model M6, cross-lagged paths from best friends' delinquency to adolescents' delinquency were unconstrained. In the final model, Model M7, all parameters that significantly improved the model fit after being freely estimated in previous models were estimated freely across personality types.

To test which paths were significantly different for the three personality types, we compared the fit of these models against the baseline model by using an adjusted chi-square difference test (Satorra \& Bentler, 2001). A significant improvement in chi-square model fit (i.e., decreasing chi-square) would be indicative of personality differences. We subsequently conducted post hoc pairwise comparisons between specific personality types to determine which personality types significantly differed from each other. In addition, we controlled for SES and gender in the final model by regressing observed scores of adolescents' delinquency on SES or gender to examine whether the cross-lagged effects were affected by these two variables.

As not all adolescents had stable friends over 3 years, to disentangle the "influence" effect from selection effects between delinquency of adolescents and their best friends over time, we conducted additional group analyses on the final model to test whether there were significant differences in cross-lagged effects between adolescents who retained the same best friends across three waves and the rest of the adolescents. Adolescents in the latter group had unstable friendships since they changed best friends at least once during the three waves and/or had their best friends participating in a maximum of two waves. Selection effects could not be examined in the unstable friendships in our sample. One reason was 
that only a small percent of adolescents in our sample changed best friends at each wave across 3 years. In addition, even when adolescents changed their best friends from one wave to another, the effect from adolescents' delinquency to their best friends' later delinquency might not only be a selection effect but also be an influence effect since the "new" best friends could already be friends with the adolescent for several years. Moreover, in unstable friendships, the effect of best friends' delinquency on adolescents' subsequent delinquency might be an influence effect of an ended friendship, or a deselection effect.

We evaluated the overall fit of the models using the comparative fit index (CFI), with values above .90 indicating satisfactory fit, and the root mean square error of approximation (RMSEA), with values up to .08 representing an adequate fit of the model (Kline, 2011).

\section{RESULTS}

The fit indices for the time-invariant model were acceptable, $\chi_{\mathrm{SB}^{2}}{ }^{2}(N=497,39)=71.88, p=.00, \mathrm{CFI}=.92, \mathrm{RMSEA}=.07$. We tested whether it was acceptable to use such a timeinvariant model by freely estimating sets of parameters across waves. Freeing paths did not improve the fit for the stability paths $\left(\Delta \chi_{\mathrm{SB}}{ }^{2}[N=497,1]=1.77, p=.18\right.$, and $\Delta \chi_{\mathrm{SB}^{2}}[N=497$, $1]=0.14, p=.70$, for adolescents' and best friends' delinquency, respectively), for cross-lagged paths from adolescents' delinquency to best friends' delinquency $\left(\Delta \chi_{\mathrm{SB}^{2}}[N=497\right.$, $1]=0.06, p=.81$ ), for cross-lagged paths from best friends' delinquency to adolescents' delinquency $\left(\Delta \chi_{\mathrm{SB}^{2}}[N=497\right.$, $1]=0.18, p=.68)$, or for correlated changes in $\mathrm{T} 2 / \mathrm{T} 3$ $\left(\Delta \chi_{\mathrm{SB}}^{2}[N=497,1]=0.94, p=.33\right)$. Hence, a fully timeinvariant model was chosen as a baseline model (M0) for the subsequent moderation analyses.

\section{Moderation Effects of Personality Types}

Table 2 presents the model comparisons of the three-group analyses, aimed at examining the moderation effects of per- sonality types. The groups based on personality types did not significantly differ on stability paths of adolescents' delinquency (M1), best friends' delinquency (M2), or T1 withinwave correlations (M3). Significant differences between personality types were found in the T2/T3 within-wave correlations (M4), however, and for both the cross-lagged effects from adolescents' delinquency to best friends' delinquency one year later (M5) and the cross-lagged effects from best friends' delinquency to adolescents' delinquency one year later (M6).

Table 3 shows the results of the final model (M7), in which T2/T3 within-wave correlations and cross-lagged effects were estimated for each personality type separately. Across personality types, both adolescents' and best friends' delinquency were relatively stable, with $\beta$ s ranging from .41 to .79 . Initial correlations between adolescents' delinquency and best friends' delinquency were positive and significant ( $\beta$ s between .14 and .29), and they did not differ significantly across personality types. T2 and T3 correlated changes varied between personality types, however. Pair-wise comparisons indicated that T2/T3 within-wave correlations between adolescents' delinquency and their best friends' delinquency were significantly stronger for undercontrolling adolescents ( $\beta$ s ranging from .20 to .21 ) and resilient adolescents ( $\beta$ s ranging from .11 to .18), as compared to overcontrolling adolescents ( $\beta$ s ranging from .07 to .10$), \Delta \chi_{\mathrm{SB}^{2}}(N=497,1)=14.81, p=.00$, and $\Delta \chi_{\mathrm{SB}^{2}}{ }^{2}(N=497,1)=5.87, p=.02$, respectively. There were no significant differences when comparing undercontrolling and resilient adolescents, $\Delta \chi_{\mathrm{SB}}{ }^{2}(N=497,1)=1.02, p=.31$.

The cross-lagged effect of adolescents' delinquency on best friends' delinquency one year later was moderated by adolescents' personality type. That is, this effect was significantly stronger for undercontrolling adolescents ( $\beta$ s ranging from .20 to .21$)$ and resilient adolescents ( $\beta$ s ranging from .11 to .14) than for overcontrolling adolescents $(\beta \mathrm{s}=.00), \Delta \chi_{\mathrm{SB}}{ }^{2}(N=497$, $1)=8.12, p=.00$, and $\Delta \chi_{\mathrm{SB}}{ }^{2}(N=497,1)=8.37, p=.00$, respectively. There was no significant difference between undercontrolling and resilient adolescents, however,

Table 2 Model Comparisons and Fit Indices for Cross-Lagged Model on Moderating Effect of Personality Between Adolescents' and Best Friends' Delinquency

\begin{tabular}{|c|c|c|c|c|c|c|c|c|}
\hline Models & $\chi_{S B}^{2}$ & $d f$ & $\mathrm{CFI}$ & RMSEA & $\Delta$ Model & $\Delta d f$ & $\Delta \chi_{S B}^{2}$ & $P$ \\
\hline MI. M0 + Stability Paths of Adolescents' Delinquency Free & 76.86 & 37 & .91 & .08 & MI-MO & 2 & 0.58 & .75 \\
\hline M2. M0 + Stability Paths of Best Friends' Delinquency Free & 69.44 & 37 & .92 & .07 & M2-M0 & 2 & 2.84 & .24 \\
\hline M3. M0 + TI Correlations Free & 67.87 & 37 & .93 & .07 & M3-M0 & 2 & 4.05 & .13 \\
\hline M6. M0 + Path Best Friends' Delinquency $\rightarrow$ Adolescents' Delinquency Free & 66.85 & 37 & .93 & .07 & M6-M0 & 2 & 5.93 & .05 \\
\hline M7. Final Model ${ }^{\mathrm{a}}$ & 53.33 & 33 & .95 & .06 & M7-M0 & 6 & 22.58 & .00 \\
\hline
\end{tabular}

Note. 'In the final model,T2 and T3 correlations, paths from adolescents' delinquency to best friends' delinquency, and paths from best friends' delinquency to adolescents' delinquency were freely estimated across personality types. 
Table 3 Parameter Estimates for Cross-lagged Model on Moderating Effect of Personality Between Adolescents' and Best Friends' Delinquency

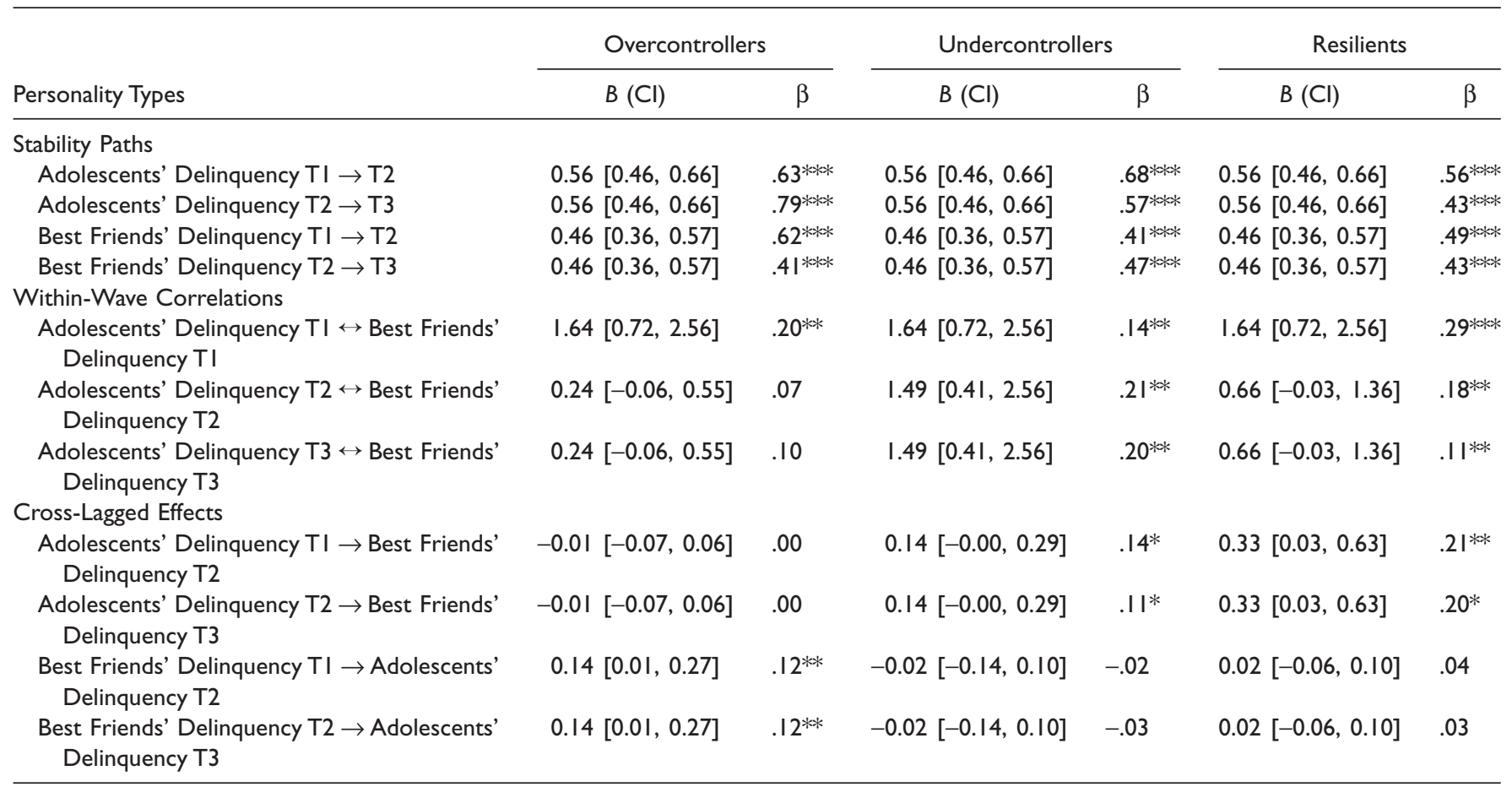

Note. $\mathrm{Cl}=95 \%$ confidence interval.

$* p<.05$. $* * p<.01$. *** $p<.001$.

$\Delta \chi_{\mathrm{SB}^{2}}{ }^{2}(N=497,1)=1.23, p=.27$. As such, adolescents with different personality types differed in the effect of their delinquency on their best friends' delinquency one year later.

The longitudinal effect of best friends' delinquency on adolescents' delinquency one year later was also moderated by adolescents' personality types. This effect was significantly stronger for overcontrolling adolescents $(\beta s=.12)$ than for undercontrolling adolescents ( $\beta$ s ranging from -.02 to -.03 ), $\Delta \chi^{2}(\Delta d f=1)=10.20, p=.00$, and marginally significantly stronger for overcontrolling adolescents than for resilient adolescents $(\beta$ s ranging from .03 to .04$), \Delta \chi^{2}(\Delta d f=1)=3.66$, $p=.055$. There was no significant difference in this effect between undercontrolling and resilient adolescents, $\Delta \chi_{\mathrm{SB}}^{2}(N=497,1)=0.24, p=.62$. Thus, personality also moderated the effect of best friends' delinquency on subsequent adolescents' delinquency.

In addition, when we controlled for SES and gender in the final model, by regressing observed scores of adolescents' delinquency on SES or gender, the results were highly similar. Confidence intervals showed that none of the cross-lagged effects between adolescents' and best friends' delinquency changed significantly after controlling for SES (i.e., the differences on $\beta$ s ranged from .01 to .03) or gender (i.e., the differences on $\beta$ s were .01). Furthermore, multiple group analysis by gender and SES also indicated no significant gender and SES effect on the cross-lagged effects of adolescents' delinquency on that of their best friends' delinquency, $\Delta \chi_{\mathrm{SB}^{2}}{ }^{2}(N=497$,
$3)=4.05, p=.26$, and $\Delta \chi_{\mathrm{SB}^{2}}^{2}(N=497,3)=1.28, p=.79$, respectively, nor of best friends' delinquency on adolescents' delinquency, $\Delta \chi_{\mathrm{SB}^{2}}{ }^{2}(N=497,3)=6.99, p=.07$, and $\Delta \chi_{\mathrm{SB}}^{2}(N=497,3)=5.07, p=.74$, respectively.

Effects in Stable and Unstable Friendships. As not all adolescents had a stable friendship across the 3 years, we compared cross-lagged effects between adolescents who had stable best friends $(n=249)$ and those who had unstable best friends $(n=190)$. To that end, we did multiple group analysis in which groups were based on different combinations of personality types and stability of friendships. We compared whether cross-lagged effects between adolescents' and their best friends' delinquency were consistent across adolescents with stable and unstable friends within each personality type. The cross-lagged effect from adolescents' delinquency on their best friends' subsequent delinquency was not significantly different between adolescents with stable and those with unstable friendships, both for undercontrollers and resilients, $\Delta \chi_{\mathrm{SB}}{ }^{2}(N=439,1)=.42, p=.58$, and $\Delta \chi_{\mathrm{SB}}{ }^{2}(N=439,1)=.13$, $p=.76$, respectively. However, the cross-lagged effect of best friends' delinquency on adolescents' subsequent delinquency was significantly stronger for overcontrollers with stable friendships ( $\beta$ s ranging from .19 to .21, $p=.01$ and .00, respectively) than for overcontrollers with unstable friendships $(\beta \mathrm{s}=.00, p \mathrm{~s}=.97$, respectively $), \Delta \chi_{\mathrm{sB}}{ }^{2}(N=439,1)=5.73$, $p=.00$. 


\section{DISCUSSION}

In this study, we aimed to investigate the moderating role of personality types in the longitudinal associations between adolescents' delinquency and their best friends' delinquency. Consistent with previous research (Haynie \& Osgood, 2005; Selfhout, Branje, \& Meeus, 2008), our study confirmed a longitudinal link between adolescents' and their best friends' delinquency over time. Importantly, however, our study indicates that the strength of the longitudinal associations between adolescents' and their best friends' delinquency is moderated by their personality types. Specifically, overcontrollers' delinquency was longitudinally predicted by their best friends' delinquency, but the delinquency of undercontrollers and resilients was not. Moreover, the delinquent behavior of resilients and undercontrollers was predictive of their best friends' delinquency over time, whereas the delinquent behavior of overcontrollers was not. The magnitudes of these longitudinal associations did not change significantly after controlling for gender and SES. Thus, our study implies that adolescents' personality types could mitigate or magnify the longitudinal associations between the delinquency of adolescents and their best friends.

\section{Longitudinal Effects between Delinquency of Adolescents and Their Friends}

These cross-lagged effects between the delinquency of adolescents and their best friends were also found when looking at stable friendships. This finding indicates that adolescents and their best friends might indeed influence each other over time on delinquency, depending on personality types. Namely, overcontrolling adolescents seem to have changed their delinquent behavior due to their best friends' delinquent behaviors. Undercontrollers and resilients seem to exert influence on their best friends' delinquent behaviors.

Further, the longitudinal associations between undercontrollers' and resilients' delinquency and their best friends' delinquency one year later did not significantly differ among adolescents with stable and unstable friendships. This result implies that the mixture of influence and selection effects occurred between adolescents' and their best friends' delinquency one year later in unstable friendships is similar to the influence effect of adolescents' delinquency on their best friends' delinquency one year later in stable friendships. This result also indicates that the effect between adolescents and their best friends could already appear in the process of befriending. However, the cross-lagged effect from best friends' delinquency to overcontrollers' delinquency was significant in stable friendships but not in unstable friendships. This result highlights the importance of stability of influence sources for the effect to occur, as in a dissolving friendship, best friends' delinquency could not exert influence on adolescents' delinquency.

\section{Understanding the Influence Process From a Developmental Perspective}

The finding that the cross-lagged effect between adolescents' and their best friends' delinquency was moderated by personality types might be understood from a developmental perspective. Individual differences in adolescents' handling of peer influences can be viewed as a process of developing toward psychological maturation (Brechwald \& Prinstein, 2011). A recent study has concluded that personality types mature in the direction of resiliency. Namely, resilients are considered more mature than overcontrollers and undercontrollers (Meeus et al., 2011). Resilient adolescents are usually described as self-confident, having high social potency such as being decisive and fond of assuming leadership roles. These developments indicate high capacity of independent thinking and self-direct one's behavior in peer interaction, which is a reflection of autonomy maturity (Allen et al., 2006; Caspi \& Silva, 1995; Hart et al., 1997). Resilients also have a well-adjusted or adaptive profile during adolescent development; in particular, they are relatively free of psychological disorders such as anxiety and depression, which are related to susceptibility to peer influence (Asendorpf et al., 2001; Cohen \& Prinstein, 2006; Prinstein et al., 2001). In addition, resilients are advanced in their social skills development and thus interpersonally effective and well liked by their peers, which in turn could provoke others to imitate their behaviors (Cohen \& Prinstein, 2006; Prinstein \& Cillessen, 2003). Therefore, their mature psychological status might make them more influential in their friendships.

On the other hand, overcontrollers seem less advanced in their development, in terms of autonomy and adaptation to the environment. They are often described as having low selfesteem and being submissive and dependent (e.g., preferring others to take charge), indicating low autonomy maturation (Caspi \& Silva, 1995; Hart et al., 1997). In addition, they are often less adaptive to the environment and prone to high social anxiety and depressive symptoms, which are related to high conformity to others' behavior (Asendorpf et al., 2001; Cohen \& Prinstein, 2006; Prinstein et al., 2001). Thus, their relatively immature psychological status might explain their susceptibility to and inability to exert influence upon their best friends' delinquency.

As for resilients, a significant longitudinal effect on their best friends' delinquency was found for undercontrollers. Their ability to influence their best friends' delinquency could also be understood from a developmental perspective, although undercontrollers are relatively less mature and maladaptive in psychological function compared to resilients (e.g., react to their environment in an aggressive way, often are less sociable, and have difficult interpersonal relationships; Asendorpf et al., 2001). Specifically, undercontrollers distinguish themselves from overcontrollers and resilients with their significantly higher level of delinquency. During adolescence, delinquency may be regarded as a way to evidence indepen- 
dence or maturation (Moffitt, 1993). Hence, with their higher delinquency, undercontrollers might in fact become a "role model" in adolescence and thus provoke their best friends to imitate their delinquent behaviors.

Undercontrollers' delinquency was not predicted by their best friends' delinquency. This finding further suggests that undercontrollers' high delinquency indeed might be only a source of influence rather than an outcome of susceptibility to pressure from their best friends. Undercontrollers are often described as impulsive and disruptive, which might account for their lower susceptibility to the influence of their best friends' delinquent behavior (Caspi \& Silva, 1995; Vitaro et al., 1997; Vitulano et al., 2010).

Although undercontrollers and resilients, in particular, may affect their friends' behavior toward more delinquency, it should of course be noted that the longitudinal associations in the current study could also be interpreted the other way around. That is, lower levels of delinquency behavior may predict lower levels of best friends' delinquency over time. An interesting question for future research is whether undercontrollers, who have higher levels of delinquency, have a more negative influence on their friends toward more delinquency and whether resilient adolescents, who have lower levels of delinquency, have a more positive influence toward fewer delinquent behaviors.

Adolescents' Personality and Their Best Friends' Personality. We found that adolescents' personality types were not related to their best friends' personality types. This is an intriguing finding given the homophily process between them. Our finding might indicate that the homophily process applies only to what adolescents do together but not to who they are. This is also suggested by a study showing medium to high similarity between adolescents and their best friends in problem behaviors such as aggression and depression, but lower and often insignificant magnitudes of similarity in Big Five personality traits between adolescents and their best friends (Selfhout, Branje, Raaijmakers, \& Meeus, 2007).

\section{LIMITATIONS AND FUTURE DIRECTIONS}

Some limitations of this study should be noted:

First, although we were able to control for selection effects by distinguishing stable from unstable friends, we were not able to examine selection effects. Future studies could examine whether individual personality types could also moderate the selection effect between adolescents and their best friends' delinquency.

Second, the sample size did not enable us to investigate an interaction between adolescents' and their best friends' personality types on the delinquency development. Future studies could examine dyadic peer influence processes, based on combinations of personality types of adolescents and their friends.
Third, friendship characteristics like reciprocity may affect influence processes between friends. However, the reciprocity of friendships at the initial wave was not related to the personality types of the target adolescents; it is unlikely that this variable accounts for the moderation effect of adolescents' personality types found in the current study.

Fourth, only adolescents' best friends were included in our study, which excluded other potentially influential contacts in the peer network. Recent research has started to assess influence processes in networks of multiple relationships while controlling for various selection effects (Kerr et al., 2012). However, the main goal of the current study was to examine the influence effects between adolescents and their best friends, and other friends' deviancy could not moderate the effect of best friends' deviancy on adolescents' delinquency (Vitaro, Brendgen, \& Tremblay, 2000).

Fifth, in this study, we used the term influence as it is commonly used in the peer influence literature. However, we have to keep in mind that even though we found longitudinal associations between stable friends' delinquency, we cannot draw causal conclusions. Moreover, we have to be aware that possible third variables might also explain the over-time association between adolescents' and their best friends' delinquency.

Finally, we did not test our hypotheses with a variablecentered approach. Using all Big Five personality traits as moderators in one model would increase the complexity of the model by adding more interaction and direct effects of personality traits. We were limited by our sample size in testing such a model. Moreover, running five separate models with each Big Five personality trait as a moderator would not have been informative of the moderating effect of a within-person personality structure. Future studies could endeavor to test our hypotheses with a variable-centered approach.

\section{CONCLUSIONS}

Despite these limitations, this study is, to the best of our knowledge, the first attempt to investigate the moderating role of personality in the longitudinal association between adolescents' and their best friends' delinquency. Our findings suggest that personality types may partly determine the extent to which youths' engagement in different forms of delinquent behavior is shaped by, or is influential upon, their best friends' engagement in delinquent behavior. Findings also suggest that resilient and undercontrolling adolescents are more likely to influence their best friends' delinquent behavior, and overcontrolling adolescents are more likely to be influenced by their best friends' delinquent behavior. Furthermore, since we found that individuals who are susceptible to being influenced by their friends' delinquency did not influence their best friends, and vice versa, it might be that in friendship dyads, adolescents are not likely influencing and being influenced at the same time. 


\section{References}

Allen, J. P., Porter, M. R., \& McFarland, C. F. (2006). Leaders and followers in adolescent close friendships: Susceptibility to peer influence as a predictor of risky behavior, friendship instability, and depression. Development and Psychopathology, 18, 155-172.

Asendorpf, J. B., Borkenau, P., Ostendorf, F., \& Van Aken, M. A. G. (2001). Carving personality description at its joints: Confirmation of three replicable personality prototypes for both children and adults. European Journal of Personality, 15, 169-198.

Bendixen, M., Endresen, I. M., \& Olweus, D. (2003). Variety and frequency scales of antisocial involvement: Which one is better? Legal and Criminological Psychology, 8, 135-150.

Block, J. H., \& Block, J. (1980). The role of ego-control and egoresiliency in the organization of behavior. In W. A. Collins (Ed.), Development of cognition, affect, and social relations (pp. 39-101). Hillsdale, NJ: Erlbaum.

Branje, S. J. T., Hale, W. W., III, Frijns, T., \& Meeus, W. H. J. (2010). Longitudinal associations between perceived parent-child relationship quality and depressive symptoms in adolescence. Journal of Abnormal Child Psychology, 38, 751-763.

Branje, S. J. T., van Lieshout, C. F. M., \& Gerris, J. R. M. (2007). Big Five personality development in adolescence and adulthood. European Journal of Personality, 21, 45-62.

Brechwald, W. A., \& Prinstein, M. J. (2011). Beyond homophily: Decade of advances in understanding peer influence processes. Journal of Research on Adolescence, 21, 166-179.

Burk, W. J., Steglich, C. E. G., \& Snijders, T. A. B. (2007). Beyond dyadic interdependence: Actor-oriented models for co-evolving social networks and individual behaviors. International Journal of Behavioral Development, 31, 397-404.

Caspi, A., \& Silva, P. A. (1995). Temperamental qualities at age three predict personality traits in young adulthood: Longitudinal evidence from a birth cohort. Child Development, 66, 486498.

Cohen, G. L., \& Prinstein, M. J. (2006). Peer contagion of aggression and health-risk behavior among adolescent males: An experimental investigation of effects on public conduct and private attitudes. Child Development, 77, 967-983.

Enzmann, D., Marshall, I., Killias, M., Junger-Tas, J., Steketee, M., \& Gruszczynska, B. (2010). Self-reported youth delinquency in Europe and beyond: First results of the second international selfreport delinquency study in the context of police and victimization data. European Journal of Criminology, 7, 159-183.

Gardner, T. W., Dishion, T. J., \& Connell, A. M. (2008). Adolescent self-regulation as resilience: Resistance to antisocial behavior within the deviant peer context. Journal of Abnormal Child Psychology, 36, 273-284.

Gerris, J. R. M., Houtmans, M. J. M., Kwaaitaal-Roosen, E. M. G., Schipper, J. C., Vermulst, A. A., \& Janssens, J. M. A. M. (1998). Parents, adolescents and young adults in Dutch families: A longitudinal study. Nijmegen, The Netherlands: University of Nijmegen, Institute of Family Studies.

Hart, D., Hofmann, V., Edelstein, W., \& Keller, M. (1997). The relation of childhood personality types to adolescent behavior and development: A longitudinal study of Icelandic children. Developmental Psychology, 33, 195-205.

Haynie, D. L., \& Osgood, D. W. (2005). Reconsidering peers and delinquency: How do peers matter? Social Forces, 84, 1109-1130.

Hix-Small, H., Duncan, T. E., Duncan, S. C., \& Okut, H. (2004). A multivariate associative finite growth mixture modeling approach examining adolescent alcohol and marijuana use. Journal of Psychopathology and Behavioral Assessment, 26, 255-270.

Junger-Tas, J., \& Marshall, I. (1999). The self-report methodology in crime research. Crime and Justice, 25, 291-367.

Kerr, M., Van Zalk, M., \& Stattin, H. (2012). Psychopathic traits moderate peer influence on adolescent delinquency. Journal of Child Psychology and Psychiatry, 53, 826-835.

Klimstra, T. A., Hale, W. W., III, Raaijmakers, Q. A. W., Branje, S. J. T., \& Meeus, W. H. J. (2010). A developmental typology of adolescent personality. European Journal of Personality, 24, 309323.

Kline, R. B. (2011). Principles and practice of structural equation modeling (3rd ed.). Guilford Press.

Lo, Y., Mendell, N. R., \& Rubin, D. B. (2001). Testing the number of components in a normal mixture. Biometrika, 88, 767-778.

Meeus, W., Van de Schoot, R., Klimstra, T., \& Branje, S. (2011). Personality types in adolescence: Change and stability and links with adjustment and relationships: A five-wave longitudinal study. Developmental Psychology, 47, 1181-1195.

Moffitt, T. E. (1993). Adolescence-limited and life-course persistent antisocial behavior: A developmental taxonomy. Psychological Review, 100, 674-701.

Muthén, B. O., \& Muthén, L. K. (2000). Integrating person-centered and variable-centered analyses: Growth mixture modeling with latent trajectory classes. Alcoholism: Clinical and Experimental Research, 24, 882-891.

Muthén, L. K., \& Muthén, B. O. (2010). Mplus user's guide (6th ed.). Los Angeles: Muthén and Muthén.

Nagin, D. S. (2005). Group-based modeling of development. Cambridge, MA: Harvard University Press.

Prinstein, M. J., Boergers, J., \& Spirito, A. (2001). Adolescents' and their friends' health-risk behavior: Factors that alter or add to peer influence. Journal of Pediatric Psychology, 26, 287-298.

Prinstein, M. J., \& Cillessen, A. H. N. (2003). Forms and functions of adolescent peer aggression associated with high levels of peer status. Merrill-Palmer Quarterly, 49, 310-342.

Robins, R. W., John, O. P., Caspi, A., Moffitt, T. E., \& StouthamerLoeber, M. (1996). Resilient, overcontrolled, and undercontrolled boys: Three replicable personality types. Journal of Personality and Social Psychology, 70, 157-171.

Satorra, A., \& Bentler, P. M. (2001). A scaled difference chi-square test statistic for moment structure analysis. Psychometrika, 66, 507-514.

Schwarz, G. (1978). Estimating the dimension of a model. Annals of Statistics, 6, 461-464.

Selfhout, M., Branje, S. J. T., \& Meeus, W. H. J. (2008). The development of delinquency and preceived friendship quality in adolescent best friendship dyads. Journal of Abnormal Child Psychology, 36, 471-485. 
Selfhout, M., Branje, S., Raaijmakers, Q., \& Meeus, W. (2007). Similarity in adolescent friendships: The role of gender. Netherlands Journal of Psychology, 63, 50-57.

Statistics-Netherlands. (1993). Standaard beroepenclassificatie 1992 [Standardized classification of occupations 1992]. Voorburg/ Heerlen: Netherlands Central Bureau of Statistics.

Sumter, S. R., Bokhorst, C. L., Steinberg, L., \& Westenberg, P. M. (2009). The developmental pattern of resistance to peer influence in adolescence: Will the teenager ever be able to resist? Journal of Adolescence, 32, 1009-1021.

Sutherland, E. H. (1947). Principles of criminology. Philadelphia: Lippincott.

Van Lier, P. A. C., Frijns, T., Neumann, A., den Exter Blokland, E., Koot, H. M., \& Meeus, W. (2011). The RADAR study: Design, description of sample, and validation of cohort assignment. Manuscript submitted for publication.

Vitaro, F., Brendgen, M., \& Tremblay, R. E. (2000). Influence of deviant friends on delinquency: Searching for moderator variables. Journal of Abnormal Child Psychology, 28, 313-325.

Vitaro, F., Tremblay, R. E., Kerr, M., Pagani, L., \& Bukowski, W. M. (1997). Disruptiveness, friends' characteristics, and delinquency in early adolescence: A test of two competing models of development. Child Development, 68, 676-689.

Vitulano, M. L., Fite, P. J., \& Rathert, J. L. (2010). Delinquent peer influence on childhood delinquency: The moderating effect of impulsivity. Journal of Psychopathology and Behavioral Assessment, 32, 315-322. 